\title{
CORRUPTION, TRANSPARENCY AND REPUTATION: THE ROLE OF PUBLICITY IN REGULATING POLITICAL DONATIONS
}

\author{
JACOB ROWBOTTOM ${ }^{*}$
}

\begin{abstract}
This article looks at the public disclosure of political donations as a case study to examine the role of transparency in addressing concerns about undue influence and corruption. The article will explore three issues. The first is to understand what it means to say that a political donation is corrupt. There is considerable disagreement on the ethics of political fundraising and this article will show how public opinion has a role in setting the standards expected of politicians. The second issue is what role the public disclosure of political donations plays in deterring and detecting corruption. While the disclosure requirements were introduced to promote greater trust in politics, it will be argued that increases in transparency have fed a growing culture of mistrust. The logic of the transparency requirements also requires the free public discussion of particular political donations and related ethical issues. The third issue is how that process of free discussion can come into tension with rights to privacy and reputation. The article will explore how the attempts to reconcile the different areas of law both reflect and shape the political culture.
\end{abstract}

Keywords: Corruption, Transparency, Political Donations, Defamation, Privacy.

\section{INTRODUCTION}

Political finance scandals are a common feature in many established democracies. In the UK, labels such as "loans for peerages" and "cash for access" are shorthand for some of the more high profile controversies in recent decades. The controversies tend to follow a familiar cycle, in which media coverage and public debate focus on whether the funding of political parties generates a form of corruption or undue influence. In most cases, subsequent official investigation will not find any concrete evidence of wrongdoing, and yet public suspicion continues to linger. The scandals are normally followed with the promise (and sometimes implementation) of reforms that aim to address problems of actual or perceived undue influence and corruption. Despite such measures, the scandals continue and the cycle repeats itself.

In some cases, the political finance scandal does not stop there and the politician or donor involved brings an action in defamation against his or her accuser. By referring the matter to a court, the political actor seeks to use a formal process to clear his or her name. Such a formal resolution can then bring a conclusion to the scandal and the political actor's reputation is not left to the mercy of public opinion.

This familiar cycle poses a number of challenges when designing a system to combat corruption and its perception, which will be the subject of this article. The first problem lies in understanding what we mean when we say a particular donation or fundraising practice is corrupt. While there is a strong desire among politicians and reformers to address perceptions of corruption, what that means beyond the obvious cases is the subject of debate. The term "corruption" can be used in a narrow sense to

\footnotetext{
${ }^{*}$ Associate Professor, University College, Oxford. Thanks to Eric Barendt for comments on an earlier draft of this article.
} 
refer to wrongdoing by an individual, or more broadly to refer to defects within the political system. As the term corruption means some form of debasement, the disagreement about how the term should apply reflects differing views about the content of the standards that have been debased. Some people see access to politicians secured through donations as a gross breach of political equality, while others see it as no more than the operation of democratic responsiveness. The first role for public opinion is therefore in debating these issues and helping to formulate the standards of conduct demanded of those in public office.

Even where there is no disagreement about the corrupt nature of a practice, the second problem lies in detecting and deterring corruption. Corrupt practices are by nature secretive and difficult to detect. In the current political climate, the public is unwilling to trust politicians to act ethically or to leave it to the police or regulators to ensure standards are being complied with. The response to these problems in the UK has been to require the public disclosure of larger political donations. The thinking behind public disclosure is that politicians and donors are less likely to engage in corrupt practices if they are being watched. The system was introduced in the hope that by making information about political donations transparent, the public would be able see for themselves the absence of any unethical practices and thereby be reassured about standards of political conduct.

In this article, it will be argued that transparency has not had this desired effect. The information about political donations disclosed under the transparency rules has raised the level of suspicion about political donations. When people see that a person has donated a large sum to a political party, they will speculate about whether that donor received anything in return. The information disclosed is enough to trigger questions about the ethics of a donation, but does not provide sufficient information to determine whether any unethical practice has taken place. The information released about political donations has been interpreted in a culture that holds the political class in low esteem and is willing to assume the worst once suspicions have been triggered.

When suspicions about the propriety of a particular donation are voiced, there can be serious repercussions for the reputation of the political actors involved. The legal protection of political reputations poses a dilemma that is the third problem to be considered in this article. The obvious response to this problem is the protection of reputation under defamation law. The difficulty with that response is that it is in tension with the rationale for transparency in political donations. The disclosure rules invite people to monitor, speculate and comment on the propriety of what they see. However, such public speculation may attract liability in defamation law, if the speaker is unable to prove the truth or otherwise defend their statement. Furthermore, by opening up the issues to public scrutiny, the disclosure of political donations transfers power to the public, allowing people to interpret events for themselves. By contrast, the law of defamation takes the issue out of the hands of the public, treats the disagreement as a private dispute, and requires the court to have final say on the interpretation of events.

The rationale for transparency points to the need for stronger protection for freedom of expression. By disclosing the identity of a donor, the transparency rules already override some of the privacy rights that normally attach to political activity. The same could also apply to rights to reputation, so that those rights are overridden in order to allow people to publicly discuss the ethics of a particular donation. The difficulty with this option is that it can allow some political reputations to be unduly 
sullied with no recompense. The courts are currently seeking to mediate between these two options in interpretation of defamation law.

Underlying these issues, we also see a tension between two cultures. The public disclosure of political donations can be seen as part of a more general shift towards a culture of transparency in politics. That culture of transparency has facilitated a shift in power to citizens and a strengthening of the mechanisms of public accountability. While the extent of the shift may not have been the intention by the framers of the transparency rules, that shift is often celebrated as a new and participatory form of democracy. The defenders of that democracy acknowledge that it can be tough and turbulent, but see the hostility towards the political class as a cost to be tolerated. Others are critical of this trend, arguing that elected politicians have ceded too much power, with the results undermining the functioning of the political system and deterring meaningful citizen engagement. This article will conclude that the way standards of political conduct are regulated can shape and have repercussions for these cultural questions.

\section{CORRUPTION}

Under the current system of political finance, parties rely on private donations to fund their activities. There is nothing intrinsically wrong with private donations and such contributions provide a way for people to express support for a party. A donation of $£ 25$ is not usually viewed with suspicion, but is seen as a positive act of political participation. What does it mean to say that a political donation or a fundraising practice is corrupt? While there are numerous laws that regulate certain corrupt practices, such as bribery, fraud and certain electoral offences, there is no single legal definition of corruption that can answer that question. The Bribery Act 2013 does not use the term "corrupt". Those laws that do refer to corruption have treated the term as "a simple English adverb”, which requires no further explanation. ${ }^{1}$ A starting point in understanding the term is to consider its general meaning as a matter of political ethics.

\section{A. Defining Corruption in Political Finance}

In recent decades, political corruption has been most commonly defined as an official's "misuse of public power for private gain", 2 or an attempt to get the official to misuse power by offering a private reward. In many cases, the line is clear - a vote or a question in Parliament relates to official duties and should not be exchanged for a political donation. People may agree on the basic definition, but often disagree on its application in more complex situations. ${ }^{3}$ Those difficulties are particularly acute in the case of an elected politician, who has a dual role as a public official and party representative. When acting in an official capacity, the politician is also expected to engage with the public and external organisations. Meeting with people, including

\footnotetext{
${ }^{1} R v$ Wellburn (1979) 69 Cr. App. R. 254 at 264, following Cooper v Slade (1858) 6 H.L. 746.

${ }^{2}$ S. Rose-Ackerman, Corruption and Government: Causes, Consequences, and Reform (Cambridge 1999), 91.

${ }^{3}$ M. Philp, “Defining Political Corruption” (1997) 45 Political Studies 436, 445; D. Lowenstein, "Political Bribery and the Intermediate Theory of Politics" (1985) 32 U.C.L.A. Law Review 784, 851. O. Kurer, “Corruption: An Alternative Approach to its Definition and Measurement” (2005) 53 Political Studies 222, 236.
} 
donors, to discuss public issues is part of a politician's job. As politicians enjoy considerable flexibility in choosing how to perform certain functions, it can be difficult to separate official conduct from other types of activity.

Various fundraising practices, such as selling access to politicians in a social setting, provoke different responses. To some, selling even social access is problematic, in so far as it allows people to use their wealth to get the attention of politicians or get a foot in the door. ${ }^{4}$ By contrast, in the US Supreme Court, Justice Kennedy stated in Citizens United that "ingratiation and access [...] are not corruption". ${ }^{5}$ Not only did Justice Kennedy find social access unproblematic, but he saw access in general as raising no corruption issues. In McCutcheon, US Chief Justice Roberts added that granting access to donors is an aspect of political responsiveness, "a central feature of democracy”. ${ }^{6}$ The Kennedy/Roberts line of thinking suggests that listening to donors is as much a part of a politician's job as listening to party members or key groups of voters. For Jackson L.J. in the English courts, selling social access is not in itself corrupt, but will depend on what happens at the social meeting. ${ }^{7}$ In his view, the politician will be open to claims of corruption if he or she reveals confidential information at the meeting, gives weight to views expressed at that occasion "merely because the proponents are donors", or gives "any form of unfair commercial advantage or preference to donors during or after those social occasions". 8

Underlying the different responses are views about the way the political system should ideally work. ${ }^{9}$ As political corruption is generally understood as a deviation from the "naturally sound condition of politics", our response to any particular practice will depend on how we think an uncorrupted system should function. ${ }^{10} \mathrm{~A}$ starting point in answering this question is to look at the specific rules governing the office holder, and ask whether a breach of the rules occurred or was induced in light of the donation. ${ }^{11}$ Paying money to ask a parliamentary question would clearly fall foul of this standard. ${ }^{12}$ To focus solely on the existing rules of office, however, is too limited as it fails to capture the ethical dimension of corruption. ${ }^{13}$ Rules regulating official behaviour are not fixed and change as new issues are identified. ${ }^{14}$ The formal rules regulating the ethical conduct of politicians are often introduced in the aftermath of a scandal. In such cases, the conduct is first identified as corrupt (even though it was not in breach of any rules at the time) and only then are rules imposed to curb similar conduct. As a result, a response of "I did not break the rules” does not automatically answer an allegation of corruption.

If existing rules alone do not identify what political conduct is corrupt, then some other basis must be relied upon to identify the ethical standards expected of a

\footnotetext{
${ }^{4}$ See B. Friedman, Democracy Ltd: How Money and Donations Corrupted British Politics (London 2013), 151.

${ }^{5}$ Citizens United v FEC, 558 U.S. 310 (2010) at 360.

${ }^{6}$ McCutcheon v FEC, 572 US _ _ (2014).

${ }^{7}$ Cruddas v Calvert [2015] EWCA Civ 171; [2015] E.M.L.R. 16.

${ }^{8}$ Cruddas v Calvert [2015] EWCA Civ 171; [2015] E.M.L.R. 16 at [28].

${ }^{9}$ See Lowenstein, n 3 above, p.784.

${ }^{10}$ M. Philp, n 3 above, p.445.

${ }^{11}$ Sometimes referred to as the "public office" definition. A. Heidenheimer (ed.), Political Corruption: Readings in Comparative Analysis (New Brunswick 1970), 4.

${ }^{12}$ Code of Conduct for Members of Parliament, (2015) HC Paper 1076 (Session 2014-15) at [11].

${ }^{13}$ See Cruddas v Calvert [2013] EWCA Civ 748; [2014] E.M.L.R. 5.

${ }^{14}$ M. Warren, "What Does Corruption Mean in a Democracy" (2004) American Journal of Political Science 328, 330-331.
} 
politician. To simply ask what conduct is in the public interest ${ }^{15}$ or can be reasonably expected of a politician ${ }^{16}$ merely restates the question without providing any direction for answering it. Alternatively, some approaches to corruption ask whether public opinion regards a particular situation as corrupt. ${ }^{17}$ The key problem with public opinion as a measure is that it describes how people react to certain situations, but does not engage with the normative issues concerning standards of conduct. An opinion poll provides a snapshot of what the public thinks, but does not tell us whether that account of corruption is over- or under-inclusive.

Reference to political theory can provide a framework to address the normative questions in defining corruption. Along these lines, Warren relies on democratic theory and the "norm of inclusion" to identify the ideal workings of the political system. Corrupt exclusion thereby occurs when a legislator is "responsive to money or power in ways that could not be justified publicly". ${ }^{18}$ Kurer relies on impartiality and non-discrimination to guide the meaning of political corruption. ${ }^{19}$ Kurer argues that cash for access violates norms of non-discrimination as the public official distributes his attention not according to who "deserves" it, but according to some non-legitimate criterion. ${ }^{20}$ Such approaches to corruption are, however, contested. As noted, Justice Roberts in McCutcheon did not share this view and saw attention to donors as a form of legitimate democratic responsiveness. References to concepts such as "inclusion" and "impartiality" provide a closer focus for the debate about ethical standards, but still do not resolve the issue.

The standards of conduct expected of public officials will normally be determined through the course of political debate. By debating and observing matters of political ethics, members of the public can shape the rules and expectations incumbent on office holders. This does not mean public opinion directly defines what actions are corrupt - an action does not become corrupt simply because respondents to an opinion poll regard it as such. However, the standards of conduct, which the corrupt act deviates from, are settled through political channels. ${ }^{21}$ Through that political process, public opinion plays a role in determining the normative standards that are referred back to when applying the concept of corruption.

\section{B. Institutional Corruption}

The discussion so far has noted the complexity in the meaning of corruption as a form of individual wrongdoing, either on the part of the official or the person seeking to induce the official. The issue is complicated further by a broader view of corruption that uses the term to critique the workings of political institutions, rather than focus on individual misconduct. In his influential work, Dennis Thompson describes "institutional corruption" as that which "encompasses conduct that under certain conditions is a necessary or even desirable part of institutional duties", but which "has a tendency to damage the legislature or the democratic process". ${ }^{22}$ According to Thompson, politicians can engage in institutional corruption without being aware of it

\footnotetext{
${ }^{15}$ See Heidenheimer, n 11 above, p.6.

${ }^{16}$ A reasonable expectation test is used in the Bribery Act 2010 s. 3-5.

${ }^{17}$ James C. Scott, Comparative Political Corruption (Englewood Cliffs, NJ 1972), 4.

${ }^{18}$ Warren, n 14 above, p.336.

${ }^{19}$ Kurer, $\mathrm{n} 3$ above.

${ }^{20}$ Ibid., pp.230-231. See also Lowenstein, n 3 above, p.828.

${ }^{21}$ Similarly, Kurer states that public opinion can provide "a criterion for evaluating” the definitions of corruption. Kurer, ibid., p.224.

${ }^{22}$ D. Thompson, Ethics in Congress (Washington 1995), 7.
} 
and by following normal practices. In the UK, David Beetham has made a similar argument to move away from the narrow meaning of corruption as the misuse of public power for private gain to an understanding of the term as "the distortion and subversion of the public realm in the service of private interests". ${ }^{23}$ Beetham's broader definition allows the language of corruption to be used to articulate objections to privatisation, large donations, lobbying and a range of other practices. ${ }^{24}$

Under the institutional definition, the system of political finance can have corrupting effects even where there is no individual wrongdoing. Politicians have to raise funds in order to fight an election and in the course of fundraising will have to meet donors and encourage future donations. The system means that politicians have to be aware of the potential to attract or alienate sources of finance when making policy choices. For Lawrence Lessig, the system of political finance in the US is a core example of institutional corruption, where the institutional arrangements for fundraising makes the legislature "dependent" on private sources of finance and thereby "less responsive to the people". ${ }^{25}$ Under this view, the politician's behaviour is not an individual transgression, but is standard practice. Any politician subject to the same pressures and incentives is likely to take on board the same considerations. Despite the difference in focus, the institutional definition is similar to individual corruption in so far as it rests on a view about how political institutions should ideally work. The crucial point for present purposes is that there is a role for the public in debating what those standards should be.

The accounts of individual and institutional corruption need not be in conflict. Those advancing an institutional account of corruption still condemn individual wrongdoing in some cases. By taking an institutional approach, we can say a donation or fundraising practice is corrupt without imputing any misconduct on the part of an individual. In practice, the division between the two types of corruption is not so neat and both the institutional and individual types of corruption can overlap. ${ }^{26}$ Even where institutional arrangements incentivise certain types of behaviour, we might still condemn the individual politician that responds to those pressures with considerable zeal. While politicians are under a general pressure to raise funds, a politician that cynically devises policies to maximise income may be thought to be further along the spectrum of corruption than the reluctant participant. That point will be relevant to the discussion of defamation law later, as the courts sometimes draw a distinction between attacks on the system of political finance and attacks on a specific political actor. A sharp distinction is not always possible or appropriate. Consequently, an individual politician may be singled out for criticism even when the main part of the critique relates to institutional arrangements.

\section{Summary}

The discussion so far has illustrated the complexities in specifying why a particular donation or fundraising practice is corrupt or thought to be corrupt. Corruption can refer to illegal conduct, unethical conduct and systemic pressures. The term political corruption, whether individual or institutional, rests on a view about the ideal

\footnotetext{
${ }^{23}$ D. Beetham, “Moving Beyond a Narrow Definition of Corruption” in D. Whyte (ed.) How Corrupt is Britain (London 2015), 41.

${ }^{24}$ Ibid.

${ }^{25}$ L. Lessig, Republic, Lost (New York 2011), p.231.

${ }^{26}$ See Thompson, n 22 above, pp.43-48.
} 
workings of the political system. When a person is alleged to be corrupt, the claim is advanced not only as a criticism of the individual, but also as a statement of the how politicians ought to behave and how the political system should function. The ideal workings of the political system are themselves contested and the subject of debate. Through political debate, public opinion plays an important role in formulating the standards that guide the application of the term.

The debate about the ideal standards of conduct poses a challenge in designing a regulatory solution to address concerns about corruption in political finance. While some people might advocate an outright ban on certain activities in the name of preventing corruption, others might see such a restriction as prohibiting legitimate political activity. That there is a division of opinion does not mean the legislature should never enact stricter controls on political practice. However, the disagreement can make transparency a seemingly appealing regulatory strategy. Furthermore, disclosure means that the legislature does not have choose a particular meaning of political corruption and can leave the matter for the public to decide.

Before turning to the transparency rules, it is important to note that a further layer of complexity arises in determining whether corrupt conduct has occurred on a particular set of facts. In the case of individual corruption, there is normally no "smoking gun" pointing to a deal or action motivated by payment. The details of a corrupt exchange will normally be known only to the two parties involved, neither of who have an incentive to go public. ${ }^{27}$ While the broad terms of the Bribery Act 2010 do not require an explicit deal for a donation to amount to a bribe, the statute will still require evidence to at least infer that the donation was an inducement or reward. Given these challenges, controls on intentional wrongdoing are not sufficient to limit even individual corruption. ${ }^{28}$ The problem of detection explains why suspicion of corruption, even in its most narrow sense, can persist even where there is no prosecution or where an official investigation finds no evidence of corruption. Having outlined the difficulties in applying the concept of corruption and its detection, the following section now turns to the role of transparency in combatting these issues in political finance.

\section{TRANSPARENCY}

\section{A. Transparency and Political Finance in the UK}

A special set of transparency rules apply to political donations. Under the current law, all donations of over $£ 7,500$ to a central political party or over $£ 1,500$ to an accounting unit of a party must be reported to the Electoral Commission. ${ }^{29}$ The Electoral Commission then publishes details including the name of the donor and size of donation on its website. During the final weeks of a general election campaign, parties are required to report donations to the Electoral Commission on a weekly

\footnotetext{
${ }^{27}$ A. Brunetti and B. Weder, “A free press is bad news for corruption” (2003) 87 Journal of Public Economics 1801, 1805 where both parties collude in the corrupt exchange. Lord John Russell, Hansard, HC Deb., vol. 130, col. 412 (10 February 1854) "all the parties engaged in the offence have an interest in concealing the acts of which they are guilty".

${ }^{28}$ Z. Teachout, Corruption in America (Cambridge, Mass. 2014), 11.

${ }^{29}$ Political Parties, Elections and Referendums Act 2000, s. 62 and Schedule 6.
} 
basis. ${ }^{30}$ Donations must come from a permissible source and foreign donations are prohibited. ${ }^{31}$ These requirements provide the main controls on political donations and there is no limit on the overall amount any person can contribute to a party or candidate. The controls were introduced in the Political Parties Elections and Referendums Act 2000 (PPERA), based on recommendations from the Committee on Standards in Public Life chaired by Lord Neill ("Neill Committee"). The Committee proposed the system of transparency as the primary means to tackle the perception that large donations secure undue influence. ${ }^{32}$

The transparency regime was proposed as a response to concerns about "sleaze" and the influence of money on politicians in the 1990s. The need for such reform reflected a long-term change in political culture, in which those in power could not take their authority or esteem for granted. This came at the same time as a number of constitutional changes that sought to promote accountability and curtail abuse of power, and thereby embody a modern democratic relationship between citizen and state. Transparency was a key element in this package of reforms, most notably with the Freedom of Information Act 2000, which sought to enable better monitoring of public institutions. Similarly, the transparency of political donations sought to allow the public to watch the flow of political contributions and be alert to any potential influence. The reformers hoped that the new settlement would restore trust to government and dampen the mood of political cynicism. As the following section will show, the effect has been the opposite and has been to institutionalise the very culture of mistrust that it sought to challenge.

\section{B. Transparency and Corruption}

Transparency is often seen to be the antidote to corruption. The names of key organisations in the anti-corruption movement, such as Transparency International or the Sunlight Foundation, underline the importance of openness to their central cause. Hand in hand with transparency is media freedom, which can help shine a light into government activity and bring matters to the public's attention. Various studies have made a connection between media freedom and lower levels of corruption ${ }^{33}$ and there are several reasons why we might expect such a result. In a democracy, accountability to the public is supposed to constrain representatives and, to some degree, ensure their actions track public opinion. When the public has limited political knowledge, the mechanisms of accountability will be weaker and leave the office-holder with greater scope to deviate from the wishes of the people. ${ }^{34}$ By informing the public, the media and other watchdog organisations enable citizens to monitor and keep representatives on a tighter leash. ${ }^{35}$

These arguments make a general case for transparency and media freedom in the name of good government. It is worth considering in further detail why transparency is seen as especially important in relation to political finance and why

\footnotetext{
${ }^{30}$ Political Parties, Elections and Referendums Act 2000, s. 63.

${ }^{31}$ Political Parties, Elections and Referendums Act 2000 s. 54.

32 The Fifth Report of the Committee on Standards in Public Life, The Funding of Political Parties in the United Kingdom (1998), Cm. 4057-I ("the Neill Committee”) at [10.1].

33 “A free press is bad news for corruption” (2003) 87 Journal of Public Economics 1801, 1805 where both parties collude in the corrupt exchange.

${ }^{34}$ For this line of argument, see A. Adsera, C. Boix and M.Payne, "Are You Being Served? Political Accountability and Quality of Government” (2003) 19 Journal of Law, Economics, and Organization 445.

${ }^{35}$ Ibid.
} 
political donations are subject to special regulations. The Neill Committee assumed that the disclosure of donations would address concerns about corruption, without fully explaining how such effects would follow. The Committee suggested that once the "the public and the media know who is financing each political party" then "rumour and suspicion wither" and "the possibility of secret influence over Ministers or policy is greatly diminished". ${ }^{36}$ This process, it was thought, would restore trust to the political system. The Committee framed the issue in terms of individual corruption and saw the problem as one of perception rather than actual impropriety, stating that suspicions of corruption are "commonly lacking in any justification". ${ }^{37}$ The thinking of the Committee was that with details of donations made public, people would not speculate about who is giving money and would see how suspicions of undue influence are unfounded. The decision to give more information to the public was therefore not an intentional act political self-flagellation by elites, but was an attempt to restore status. Had this strategy worked, the increased trust in politicians may have enhanced the long-term power of government by bolstering the authority of elected officials. ${ }^{38}$ As will be argued, these expectations were wide of the mark. Nonetheless the assumptions of the Neill Committee continue to be made in the discussion of political donations. ${ }^{39}$

Underlying the Committee's assumption about the benefits of transparency is a view about how transparency will work. If the public is to be reassured of the absence of corruption by the publication of the data, then the logic of the argument is that disclosure is also capable of revealing to the public the presence of any corrupt donations. If the system works in this way, the disclosure regime should then have a deterrent effect, as any corrupt payments will be exposed and subject to the appropriate legal, regulatory or political sanctions. While the transparency regime was introduced with these effects in mind, the question remains as to how donations data can reveal the presence or absence of corruption.

The US election law scholar Richard Briffault has identified two possible mechanisms through which donation transparency might be thought to tackle corruption. The first is simply that publicity will deter people from making large donations in general. Such a mechanism, Briffault writes, assumes that large donations are "inherently wrongful and corrupt" and that "public disclosure of these contributions would cause such public outrage that donors would be too embarrassed to give or candidates too ashamed to accept them". ${ }^{40}$ If this is the goal of the UK controls, its success has been limited at best. Some very large donations were made during the early years of the PPERA and attracted considerable attention. ${ }^{41}$ While that publicity may have deterred some people from making headline-grabbing donations, donors continue to give some very large sums to political parties. ${ }^{42}$

\footnotetext{
36 The Neill Committee, n 32 above, at [4.15].

${ }^{37}$ Ibid., at [4.5].

${ }^{38}$ For discussion of the use of transparency to increase the authority of government, see J. Ferejohn,

“Accountability and Authority: Toward a Theory of Political Accountability” in A. Przeworski, S.

Stokes and B. Manin (eds.) Democracy, Accountability, and Representation (Cambridge 1999).

${ }^{39}$ For example, the point was made in debates about extending donation disclosure to Northern Ireland. See House of Commons Northern Ireland Select Committee, Draft Northern Ireland (Miscellaneous Provisions) Bill (2013), HC Paper1003 (Session 2012/13), at [13]. Electoral Commissioner Anna Carragher told the Committee that transparency would "build trust and confidence”, see Q461.

${ }^{40}$ R. Briffault, “Campaign Finance Disclosure 2.0” (2010) 9 Election Law Journal 273, 281.

${ }^{41}$ For example, in 2001 Sir Paul Getty donated £5 million to the Conservative Party.

${ }^{42}$ In March 2014, Sir Michael Hintze made a single donation to the Conservative Party of over £1.5 million. Over 2015, the trade union Unite gave just under £2.9 million to the Labour Party.
} 
Deterring large donations is not, however, the goal of the UK disclosure laws. The Neill Committee did not know what the impact of disclosure would be on large donations, and saw a reduction in large donations as a "risk" rather than a desirable goal. ${ }^{43}$ The Committee stated that it remained "perfectly possible" that large donations would continue ${ }^{44}$ and did not think disclosure was "likely to reduce the level of donations significantly". ${ }^{45}$ In any event, the Committee thought that the dependence of a party on a particular source is "its own affair, provided its dependence is a matter of public knowledge". ${ }^{46}$ The Committee's reasoning suggested that large donations alone do not raise any ethical issues and the purpose of disclosure is not to shame large donors. Since the Neill Report, the Committee on Standards in Public Life under the chairmanship of Sir Christopher Kelly found that the dependence on large donations is "unhealthy" for democracy, that public suspicion was justified, and called for an end to the "big donor culture". ${ }^{47}$ Since the transparency regime was implemented, many commentators have come to share the view that big donations are not a desirable feature of politics. However, the primary reform that is proposed to deal with big donations is to cap on the maximum sum that can be given to a political party and offer some public funding. Transparency is not advanced as the mechanism to reduce the dependence on large donors. ${ }^{48}$

If the transparency regime does not aim to tackle corruption by deterring all large donations, then it must offer some way of distinguishing donations that are potentially suspect from those that are not. This leads to the second mechanism discussed by Briffault, in which the public looks at the data to decide for themselves which donations are suspect, and will then "punish the candidate appropriately at the polls". ${ }^{49}$ In Buckley $v$ Valeo, the US Supreme Court stated that a "public armed with information about a candidate's most generous supporters is better able to detect any post-election special favors that may be given in return". ${ }^{50}$ In the UK, Lord Shore, a member of the Neill Committee, advanced a similar argument in the parliamentary debates on the PPERA, stating that disclosure allows the public to know:

who is contributing and whether the motives for the contribution are entirely above board, or whether they are suspect or open to criticism. We can then develop the case. ${ }^{51}$

In the same debate, Lord Goodhart, another member of the Neill Committee, stated:

If we know where the money is coming from, we can scrutinise the behaviour of the party which receives it. Is the party going out of its way to take action, or to avoid taking action, in ways that will benefit the donor? Is there a quid pro quo for the donations? If the information about the donations is in the

\footnotetext{
43 The Neill Committee, n 32 above, at [4.39].

${ }^{44}$ Ibid., at [4.39].

${ }^{45}$ Ibid., at [7.24]. Though compare [8.7].

${ }^{46}$ Ibid., at [6.7].

${ }^{47}$ Thirteenth Report of the Committee on Standards in Public Life, Political Party Finance: Ending the big donor culture (2011), Cm. 8208.

${ }^{48}$ Some MPs recognised this in the parliamentary debates on the PPERA, see Martin Linton MP, Official Report of Standing Committee G, Political Parties, Elections and Referendums Bill, cols.1245 (27 January 2000).

${ }^{49}$ Briffault, n 40 above, p.286, citing K. Sullivan, “Against Campaign Finance Reform” (1998) 1998 Utah L. Rev. 311, 326.

${ }^{50}$ Buckley v Valeo (1976) 424 US 1 at 67.

${ }^{51}$ HL Deb., vol. 611, col.1130 (3 April 2000). For similar arguments in the UK, see for example Robert Walter MP, Official Report of Standing Committee G, Political Parties, Elections and Referendums Bill, cols. 131-132 (27 January 2000). Naomi Long MP, Hansard, HC Deb., vol. 564, col. 82 (24 June 2013).
} 
public domain, the press and the other political parties will be watching to see what the donor gets out of it. If the information is kept secret, the watchers do not know where to start. ${ }^{52}$

Under this approach, it is for the public to decide whether a particular donation was corrupt.

Publicity can aid the formal controls on corrupt conduct. Transparency allows people to look at the data and alert the relevant authorities, such as the police, if they suspect any impropriety. However, notifying the official authorities cannot be the sole aim of transparency. As the previous discussion highlighted, corruption is not limited to illegalities or breaches of existing rules, so in some cases the suspected impropriety is not subject to the jurisdiction of the authority. For such cases, public opinion remains the final arbiter. Even where the complaint does fall within the authority's jurisdiction, a single complaint from a suspicious individual may not be sufficient to spur the regulator into action. To prompt the authority it may be necessary to mobilise public opinion to show that there is serious concern. Those considering whether to complain may need to discuss their concerns openly to test the issue. Finally, as the regulators face evidential limits in detecting any impropriety, public opinion provides a separate type of control.

Leaving the public to make up their own minds has considerable appeal given the grey areas in defining corruption and interpreting the disclosed facts. ${ }^{53}$ Public opinion, however, provides a messy and inconclusive process in which ethical questions about corruption are fused with more general political questions about the sources of finance. A donation from a tobacco company lobbyist may attract criticism from those who see the money as securing undue influence, and from those who object to the political goals of the lobbyist. In political debate, the two lines of argument may not be clearly separated.

The ability of the public to detect corruption is hindered by the limited nature of the information disclosed under the transparency regime. ${ }^{54}$ To interpret the data and decide which donations are suspect, the public need more contextual information. The complexity of the information necessary to contextualise the donations data can make the public assessment particularly difficult. For example, discovering the true controller of a company that made a political donation can be a challenging task for even an experienced financial journalist. The most important contextual information may remain undisclosed as a result of such complexities, and even when disclosed the significance of such details may not be fully understood by the non-specialist.

Aside from complexity, disclosure has other limitations in combating corruption. As Lawrence Lessig has pointed out, transparency regimes do not show why a person gave money to a political party, how a party reacted to the donation (or the prospect of further donations), or what was actually said in a meeting between an official and a donor. ${ }^{55}$ The limits of the data explain why the activities of the media in discovering additional information are important. These activities sometimes rely on Freedom of Information Act requests, published documents and inside sources, to find out who met whom and whether any benefits have been granted. The media sting operation can aid the process by reconstructing a typical meeting between a politician and prospective donor, and showing what a politician tends to say in such situations.

\footnotetext{
52 HL Deb., vol. 611, col. 1136 (3 April 2000).

53 See K. Sullivan, "Political Money and Freedom of Speech” (1997) 30 University of California Davis Law Review 663, 681-682.

${ }^{54}$ See discussion in L. Lessig, “Against Transparency”, The New Republic, 9 October 2009.

${ }^{55}$ Lessig, Republic, Lost, n 25 above, pp.257-260.
} 
While the use of such press tactics is controversial and raises ethical questions, the media sting shows the type of culture in which people make large donations and in turn provides a context in which the donations data can be interpreted. However, the information uncovered in the sting operation will still be open to interpretation and whether it provides damning evidence or not will be subject to debate. More generally, the sting operation does not provide concrete evidence of wrongs occurring in other situations when undercover journalists are not present.

The limited information disclosed does not mean we should demand evercloser surveillance of politicians. Cain notes that the case for transparency could be taken to a logical extreme by requiring public officials to carry small cameras to log and disseminate their every conversation and movement. ${ }^{56}$ Cain uses the example to show how such extreme measures would have undesirable consequences, such as the infringement of privacy and the removal of the representative's "deliberative space", as well as overloading the public with information. ${ }^{57}$ Even with such maximal disclosure, the public would find that the decision-making process lacks simple chains of causation and is subject to many competing pressures. More complete transparency may well provide a picture that is too muddy to provide any simple account of how a donation influenced a decision. As a result, full disclosure is unlikely to reassure the public that a donation had no influence whatsoever on a politician.

The limitations of the donations data and the challenges in interpreting the information shows why the system under the PPERA has failed to restore trust in the system of political finance. The more information people have, the greater scope for suspicion. If the data reveals that a person has donated over $£ 100 \mathrm{k}$ to a political party, many people will ask why that donation was made and will speculate as to the possible motives. ${ }^{58}$ The information is also interpreted in the context of a political culture that is highly critical of politicians. As Lessig notes, instead of reassuring the public, greater transparency merely fuels speculation and sustains the political culture of mistrust. ${ }^{59}$

The culture of mistrust may, however, be no bad thing and act as a counterweight to the institutional pressures that encourage politicians to respond to donors. The potential for any interactions to be viewed as suspect may make both the politician and donor more cautious, even where there is no wrongdoing. While publicity provides a general pressure, it is not a precise instrument. In some cases, the public may rightly regard a donation as corrupt, even where the evidence is limited. In other cases, however, the data and the circumstantial evidence may result in a donor or politician being unfairly censured by public opinion. Alternatively, the limited evidence may result in some corrupt practices going undetected. The question, then, becomes to what extent the inconclusive and potentially damaging nature of the process of transparency should be accepted as the price for an open political system. The answer, it will be argued later, partly depends on one's view of the political culture.

\section{Detecting Patterns of Corruption}

\footnotetext{
${ }^{56}$ B. Cain, Democracy More or Less (Cambridge 2015), 42-43.

${ }^{57}$ Ibid., p.43.

58 See Lessig, n 54 above.

59 Ibid,
} 
Transparency is not only useful for journalistic investigations into a specific decision or contribution. Academics and other specialists can analyse donations over a period of time to identify patterns that are indicative of corruption in a system. A recent study conducted by Mell, Radford and Thevoz found a statistically significant relationship between making a large donation and being nominated for a peerage. ${ }^{60}$ The authors concluded that the chance of the pattern being a coincidence was about as likely as "entering Britain's National Lottery five consecutive times, and winning the jackpot on each occasion". ${ }^{61}$ The study does not make a specific allegation of corruption, but shows that it is not unreasonable to suspect that corruption - whether as individual exchanges or systemic pressures - lurks somewhere within the system of political honours.

By facilitating an analysis of the patterns of donations, transparency is seen as an important check on institutional corruption. Ansolabehere writes that such studies are useful for examining "more systemic concerns regarding the extent to which, legal or ethical violations aside, donors can gain value through their contributions". ${ }^{62}$ Using donations data in this way, numerous studies in the US have sought to evaluate links between contributions by particular industry sectors and political decisions. The disclosure of donations can thereby play a role in detecting systemic biases.

The statistical analysis of donations data also comes with limits. The studies that attempt to measure a relationship between decisions and patterns of donations are constrained by the available data. ${ }^{63}$ In some cases of potential donor influence there will be no recorded decision that researchers can use in a study. Influence secured through a private conversation with a political aide may not show up in a vote or policy decision. ${ }^{64}$ Baumgartner et al note that a donation may be given to an official as "an insurance policy" in order to "keep access open and not to antagonize" or as an effort "to keep friendly faces" in the legislature. ${ }^{65}$ Consequently, influence may be secured in ways that are not manifested in a legislative vote, and cannot be reduced to a simple matter of "winning" or "losing". 66 The potential effects of money can be subtle and hard to observe given the complex and varying dynamics that shape particular political decisions.

The long-term statistical studies are less likely to generate the high profile scandals found in journalistic reports. That is both a strength and weakness. By avoiding a specific allegation, the academic studies are less likely to damage the reputation of a particular political actor. However, the academic study will be less powerful in mobilising public opinion. A sober analysis of donation trends is likely to remain in an academic journal rather than make front page news. Such studies have less potential to impose a political cost and therefore have less of a deterrent effect on corrupt arrangements. The study of patterns in political finance performs a diagnostic function, rather than imposing an informal sanction on political behaviour.

\footnotetext{
60 A. Mell, S. Radford and S. Thevoz, "Is There a Market for Peerages? Can Donations Buy You a British Peerage? A Study in the Link Between Party Political Funding and Peerage Nominations, 200514” (2015) Oxford University Department of Economics Discussion Paper Series 744.

${ }^{61}$ Ibid.

${ }^{62}$ S Ansolabehere, "The Scope of Corruption: Lessons from Comparative Campaign Finance

Disclosure” (2007) 6 Election Law Journal 163, 164.

${ }^{63}$ For discussion of these limits see M. Gilens, Affluence and Influence (Princeton 2012), 243-247.

${ }^{64}$ Ibid., p.246.

${ }^{65}$ F. Baumgartner, J. Berry, M. Hojnacki, D. Kimball and B. Leech, Lobbying and Policy Change (Chicago 2009),193.

${ }^{66}$ Gilens, n 63 above, p.246.
} 


\section{The Proliferation of Rules and Secondary Scandals}

Aside from the limits of transparency in controlling corruption, there are other reasons why transparency rules are unlikely to generate trust. The system of transparency contains a number of technical rules regulating donations. As a result there are more rules that can potentially be broken, and therefore more allegations of breaches of rules can be made. That in turn can "increase the apparent prevalence of misconduct". ${ }^{67}$ This proliferation of rules and controls, gives rise to another feature of modern politics - the increasing focus on secondary issues about compliance with the rules, rather than with the primary ethical violation that the rules were intended to curtail. In his study of political scandal, John Thompson discusses secondary scandals about cover-ups where "attention is shifted from the original offence to a series of subsequent actions which are aimed at concealing the offence". ${ }^{68}$ With political finance, the secondary issues of compliance tend to focus on whether the donation was properly disclosed, whether the disclosed data provided the name of the true donor, whether the money was given by a permissible donor, etc. However, such controversies arise even where there is little evidence of corruption. The secondary issue of compliance is treated as a proxy for the ethical question and becomes the centre of attention. The fact that a donation was not properly disclosed is taken as evidence that the parties had something to hide and the donation is assumed to be "dodgy".

It is easy to see why the media will tend to seize on such secondary issues, as the compliance issues are governed by more concrete rules, posing fewer definitional and evidential challenges than the ethical issues. The secondary issues of compliance can also become the focus of the politician's defence in public debate, even when an allegation relates to the ethics of a donation. When challenged about an allegedly "dodgy" donation, it is common to hear party officials responding that a donation was fully disclosed and made in compliance with all the laws. However, both the analysis of the meaning of corruption and the assumed workings of transparency suggest that disclosure should be the start of a conversation about the ethics of a donation and not the end of it. A failure to disclose a donation may raise suspicion, but full disclosure under the rules alone does not put it above suspicion.

\section{E. Summary}

To summarise, transparency is often taken to be an antidote to corruption. It is certainly the case that secrecy facilitates corruption and that transparency is a necessary element for scrutiny. However, the analysis shows that the publication of donations data does not by itself provide an antidote. Transparency must be accompanied by a culture in which the data can be analysed and further investigations undertaken to contextualise that information. For the transparency regime to work through the channels of political accountability, people need to speak out and ask difficult questions when something does not look right. Even where an investigation has been conducted and publicly debated, the process does not provide a definitive answer to any ethical concerns. Transparency is often seen to be the least restrictive

\footnotetext{
${ }^{67}$ N. Allen and S. Birch, Ethics and Integrity in British Politics (Cambridge 2015), 35, see also 183.

${ }^{68}$ J. Thompson, Political Scandal: Power and Visibility in the Media Age (Cambridge 2000), 17.
} 
form of regulation, as it does not prohibit certain political donations. However, transparency imposes some significant costs. The process is an imprecise mechanism, and reputations can be damaged unduly while some errant politicians may escape censure. The following section will consider these costs in further detail, looking at the impact of the transparency regime on individual rights to privacy and reputation.

Before moving on, it is important to note that whatever the limits limits in combating corruption, transparency still serves a number of other purposes. For example, donations data can provide useful information to the public about a candidate or party. ${ }^{69}$ Some people might impose a sanction against a political party not because there is anything "dodgy" about its sources of income, but because they do not like parties that, for example, rely on large donations, take money from a criminal or a tax avoiding company, or from a particular interest group. More generally, donations data might show that a party takes money from particular organisations or industry sectors, which can be interpreted as a type of endorsement. Such donation patterns might lead the voter to make a positive or negative assessment of the party. The donations data provides an information shortcut that can be relevant to the assessment of a political party. ${ }^{70}$ While there are shortcomings in relying on donations as a shortcut, ${ }^{71}$ the use of the data in this way shows that the case for transparency does not rest solely on anti-corruption arguments.

\section{PRIVACY AND REPUTATION}

\section{A. Privacy}

Political beliefs are an element of private life and, as such, can be protected under both the law of misuse of private information and data protection. ${ }^{72}$ In so far as donations data reveals a political affiliation, privacy rights may be engaged. The PPERA strikes a balance between privacy and transparency by requiring the disclosure of only those donations above the relevant threshold, currently fixed at $£ 7,500$ per for donations to the central party. The relatively high threshold gives considerable protection to donors and contrasts with US federal law, in which donations of more than $\$ 200$ must be disclosed. ${ }^{73}$ The protection provided by the threshold for disclosure in the UK may also be too broad in scope, as it covers donations from companies and institutions that do not hold personal privacy rights.

The rationale for the balance struck is that any donation below the disclosure threshold is unlikely to pose a danger of undue influence and only with "significant" donations is it "credible to suppose that there could be some improper purpose underlying the donation". ${ }^{74}$ That assumption is open to question, as corrupt exchanges

\footnotetext{
${ }^{69}$ Buckley v Valeo (1976) 424 US 1 at 66-67, the US Supreme Court stated that the donations data can "aid the voters in evaluating those who seek federal office".

70 See E. Garrett, “Voting with Cues” (2003) 37 U. Rich. L. Rev. 1011.

${ }^{71}$ See W. McGeveran, “Mrs. McIntyre’s Chequebook: Privacy Costs of Political Contribution Disclosure” (2003) 6 U. Pa. J. Const. L. 1, 24-29, querying the usefulness of donations data in relation to voting decisions.

${ }^{72}$ Applause Store Productions v Raphael [2008] EWHC 1781 (QB); [2008] Info. T.L.R. 318 at [80] and the Data Protection Act 1998 s. 2.

${ }^{73}$ See 52 U.S.C. 30104.

${ }^{74}$ The Neill Committee n 32 above at [4.32]. However, as noted earlier, the Committee did not assume that all donations above that threshold were corrupt, but rather that such donations had the potential to generate suspicion.
} 
can be made with relatively small sums of money, depending on the benefit being sought and the likelihood and consequences of being caught. ${ }^{75}$ However, bigger donations seem more likely to generate leverage with the office-holder and the balance struck seems to reflect a rule of thumb that the public has greater concern about the larger sums. In the case of bigger donations, the public interest in transparency and public monitoring outweighs any privacy interests. Furthermore, the data released by the Electoral Commission has a limited impact on privacy, as the information on the published register does not include the address of an individual donor. ${ }^{76}$

The concern with privacy is not solely about the quantity of information released, but also with the way that information is used. For example, by revealing a political affiliation a person may suffer negative responses from others. For this reason, US federal law provides an exception for donations to small political parties where there is a probability that disclosure will expose the donor to "threats, harassment, or reprisals from either Government officials or private parties". ${ }^{77}$ In the UK, there is no general exemption for victimisation. However, a special exception was made for Northern Ireland, as the sensitive political divisions increased the risk of adverse treatment. As a result, donations to parties in Northern Ireland are exempt from the general disclosure requirements, though moves to increase transparency are being undertaken. ${ }^{78}$

Aside from harassment and threats, the public disclosure of donations may have less dramatic consequences that can nonetheless chill political activity. William McGeveran argues that the impact of such disclosures may be subtle and rest on the "everyday social pressures and the human desire to conform", which lead people "whose opinions differ from those around them" to "disengage from political activity if that is the only way to avoid disclosure". ${ }^{79}$ McGeveran also warns that donations can be combined with other information, such as addresses and places of work, to create "digital dossiers". ${ }^{80}$ The argument is less persuasive in relation to large donations, which represent significant attempts to influence the political process and should not be shielded from social accountability. Such concerns are more convincing in the case of very small donations, which in the view of the US Supreme Court are "likely to be especially sensitive to recording or disclosure of their political preferences" ${ }^{81}$ By limiting the disclosure of small donations, UK law already goes some way to protect such privacy interests. ${ }^{82}$ If anything, the current laws err too far on the side of privacy in fixing a high threshold for disclosure. The primary protection for privacy should come through specific laws that control the use of such data, rahher than through non-disclosure.

\footnotetext{
75 The Neill Committee proposed a lower threshold for accounting units, because smaller sums were more likely to have leverage over local decisions, n 32 above at [4.35].

${ }^{76}$ Political Parties, Elections and Referendums Act 2000 s.69(4).

${ }^{77}$ Buckley v Valeo (1976) 424 US 1 at 74. See also Brown v Socialist Workers '74 Campaign Committee (Ohio) (1982) 459 U.S. 87.

${ }^{78}$ See Northern Ireland (Miscellaneous Provisions) Act 2014, granting power to increase levels of transparency.

${ }^{79}$ W. McGeveran, “Mrs. McIntyre’s Persona: Bringing Privacy Theory to Election Law” (2011) 19

Wm. \& Mary Bill of Rts. J. 859.

${ }^{80}$ Ibid.

${ }^{81}$ Buckley v Valeo (1976) 424 US 1 at 83.

${ }^{82}$ Briffault calls for the US to adopt a model closer to the UK's in which only larger donations are disclosed. See Briffault, n 40 above, p.294.
} 
If privacy is to be protected by controlling the conduct of the recipients of the data, then a further question is whether privacy law will restrict media investigations prompted by a disclosed donation. If a journalist is to investigate who met whom on a social basis or when a politician spoke to a particular donor, then there is a clear risk of interfering with aspects of private life. Whether such research infringes privacy rights will depend on the nature of the information disclosed by the media and how it was acquired. As noted earlier, the public is not entitled to the constant surveillance of politicians. However, given that the rationale for the transparency regime requires such investigations, there is a strong case for arguing that genuine research into donors and politicians should be protected as a matter in the public interest and outweigh the privacy rights.

\section{B. Reputation}

The earlier discussion showed that the incomplete information in the transparency regime means that commentators will sometimes "join the dots" between a donation and a decision, or engage in further investigations and research. The secretive nature of corrupt practices means that the process of scrutiny will rely on speculation and circumstantial evidence, which can impose a significant risk of error when suggesting that an impropriety has occurred. An error can have a devastating effect on the reputation of a politician and can lead to the sudden end of a career and public humiliation.

Given the high stakes, those making allegations of corruption or misconduct risk a defamation action being brought against them. For example, Peter Cruddas and Tim Yeo have brought actions in relation to sting operations by investigative reporters from The Sunday Times. ${ }^{83}$ Sting operations in particular pose a litigation risk, given that such reports are likely to be high profile, have damaging effects and carry the authority of a well-known team of reporters. In Australia, Federal Treasurer and Liberal Party MP Joe Hockey brought a defamation action following several publications making claims of donors gaining privileged access. ${ }^{84}$ Less sensational comments also face a risk. A Scottish National Party councillor faced a libel action after publishing a press release, which a Labour Party donor claimed carried an innuendo that he had given money to influence local planning decisions. ${ }^{85}$ In the runup to the 2015 general election, in various newspaper reports commenting on disclosed donations, Conservative Party spokesmen issued a standard response that all donations were in compliance with the legal regulations and that "Any suggestion of impropriety by the party is malicious and defamatory and will be treated as such". ${ }^{86}$ Such statements give a clear warning to any would-be critics.

\footnotetext{
${ }^{83}$ Cruddas v Calvert [2015] EWCA Civ 171; [2015] E.M.L.R. 16, Yeo v Times Newspapers [2015] EWHC 3375; .

${ }^{84}$ Hockey v Fairfax Media Publications Pty Limited [2015] FCA 652. The claim failed in relation to the full newspaper articles, but was upheld in relation to posters and messages on Twitter with the words "Treasurer for Sale".

${ }^{85}$ Massie v McCaig [2013] CSIH 14; 2013 S.C. 343, in which the appeal court refused an interim interdict, in part stressing the free speech implications and the protection given to fair comment. The action for damages was dropped following a public apology from the councillor, see Aberdeen Evening Express, 28 October 2014.

${ }^{86}$ For several examples, see, “Call for east Runcorn MP to explain 'coincidence' of donation and absence from plain packaging vote” Liverpool Echo, 25 March 2015; "Political donations: Secretive groups have funnelled £7.35m to Tory politicians”, Mirror, 19 March 2015; “Opaque organisations
} 
In a libel action, the court has to determine the meaning of the article to decide whether it made an allegation of corruption, and what type of corruption it alleged. The publisher should therefore take care when presenting its analysis of donations to make the meaning clear and avoid any unnecessary imputations. The media might be expected to separate allegations of individual corruption from institutional corruption. While such an expectation is reasonable in some cases, the earlier discussion argued that precise lines between individual responsibility and systemic pressure are not always possible or appropriate to draw. The people subject to systemic pressures may bear some responsibility for perpetuating that system and be targets for criticism. Furthermore, an article laden with caveats to avoid any possible misinterpretation may lose its force. The language of corruption may be more sweeping and likely to damage reputations, but is more likely to mobilise public opinion. Precision in meaning may be harder still in short social media messages. For example, a short message on Twitter to promote an article will normally be attention-grabbing and lack context, and thereby pose more of a risk to reputation. ${ }^{87}$ While libel actions are relatively rare, the message is clear - reporting on political donations carries a risk and it is sometimes difficult to avoid claimants alleging a defamatory meaning when discussing issues of political ethics. The risk raises two issues that will be discussed below. The first is the potential to curtail freedom of political debate and short-circuit the process of public scrutiny. The second issue relates to the role of the court in settling such disputes.

\section{Freedom of political discussion and corruption}

The potential for libel actions not only raises the familiar problems of chilling political speech, but also curtails the very discussion on which the transparency regime depends. By publishing raw data, the transparency regime encourages the people to interpret the data, speculate and ask difficult questions. The potential negative publicity generated by speculation is the mechanism that is expected to deter donations that are corrupt or be seen as corrupt. The potential for negative publicity of the sort that defamation law guards against is the political sanction at the heart of the transparency.

Traditionally, English libel law gave considerable protection to the politician's reputation, as it did for any person. ${ }^{88}$ In the Victorian case of Campbell $v$ Spottiswoode, Cockburn CJ stated that "public affairs could not be conducted by men of honour with a view to the welfare of the country, if we were to sanction attacks upon them, destructive of their honour and character, and made without any foundation". ${ }^{89}$ An imputation of a corrupt motive was seen to be particularly damaging. The goal of protecting the honour and authority of the politician belongs to an earlier political culture, which has since given way to greater openness and accountability. That shift has been accompanied by greater protection for expression rights on matters of public interest. Along these lines, numerous judicial statements

give Tories nearly £500k in concealed donations”, Guardian, 14 March 2015; “Tory’s U-Turn Over Vow to Return Donation” Daily Mail, 18 February 2015; “Tory MPs were given donations by businessman in £13m tax battle”, Evening Standard, 17 February 2015; "Invitations go out for Conservative fundraiser”, Guardian, 16 December 2014.

${ }^{87}$ Hockey v Fairfax Media Publications Pty Limited [2015] FCA 652.

${ }^{88}$ Silkin v Beaverbrook Newspapers Ltd [1958] 1 W.L.R. 743 at 746.

${ }^{89}$ Campbell v Spottiswoode (1863) 3 B. \& S. 769. 
have found that political figures must tolerate stronger criticism. In Branson v Bower, Eady J. stated

In a modern democracy all those who venture into public life, in whatever capacity, must expect to have their motives subjected to scrutiny and discussion. ${ }^{90}$

Steps were taken in that direction in the year before the PPERA and Freedom of Information Act were enacted, when the House of Lords recognised a public interest defence in Reynolds, ${ }^{91}$ which was later re-formulated by s. 4 of the Defamation Act 2013. Earlier, the courts had also ruled that government bodies and political parties cannot bring a claim in defamation. ${ }^{92}$ More recently, the courts have stated that where political expression is at stake, an “over elaborate analysis” of the publication's meaning should be avoided. ${ }^{93}$

The greater freedom accorded to political expression can be seen as part of a realignment of power between politicians and the people. By restricting the ability of others to damage a person's reputation, the law of defamation gives the subject of the statement some control over what can be said. The liberalisation of libel law removes some of this control where matters of public interest are concerned and thereby removes the politician's power over their reputation and redistributes it to the public. Such a redistribution is important not only because the discussion of public affairs can include matters implicating a person's reputation, but also because reputation is a key political resource in itself. It is a resource that political actors rely on for the attainment of power and support from their peers and the public. ${ }^{94}$ As a source of power, political reputations are contested, challenged and fought out before the public. The liberalisation of libel represents a "politicisation" of reputation, and can be seen alongside the constitutional reforms from the late 1990s.

The protection of political expression is most obviously found in the defences of honest opinion and the public interest. However, the defences still have limits and the legal support for the redistribution of communicative power only goes so far. Honest opinion is only available where the defendant can show the statement was one of opinion rather than fact. With an allegation of corruption, that will depend on the context and presentation of the statement. ${ }^{95}$ The fact that the meaning of corruption is open to debate will not make all such allegations matters of opinion and some allegations of corruption will be statements of fact. The public interest defence is available where the statement is on a matter of public interest and the defendant reasonably believed that it was in the public interest to publish the statement. ${ }^{96}$ The defence was established in the Defamation Act 2013 and is as yet untested. While allegations of political corruption will normally relate to matters of public interest, the protection offered by the defence will depend on how the reasonable belief standard is interpreted, and whether any conditions are implied into that standard. It seems likely that the court will require the defendant to show that at least some steps were taken to check and verify the allegations prior to publication. ${ }^{97}$

\footnotetext{
${ }^{90}$ Branson v Bower (No 2) [2002] Q.B. 737 at [25].

${ }^{91}$ Reynolds v Times Newspapers [2001] 2 A.C. 127.

${ }^{92}$ Derbyshire County Council v Times Newspapers [1993] A.C. 534; Goldsmith v Bhoyrul [1998] Q.B. 459.

${ }^{93}$ Waterson v Lloyd [2013] EWCA Civ 136; [2013] E.M.L.R. 17 at [66].

${ }^{94}$ Thompson, n 68 above, p.23.

${ }^{95}$ See Yeo $v$ Times Newspapers [2014] EWHC 2853 (QB); [2015] 1 W.L.R. 971 at [97].

${ }^{96}$ Defamation Act 2013, s.4.

${ }^{97}$ See Yeo v Times [2015] EWHC 3375 at [29], and at [136] where Warby J. notes that the principles of Reynolds privilege "flow from the principles established in Strasbourg" under the ECHR.
} 
The legal decisions continue to send out mixed signals about the treatment of allegations of illegal or corrupt practices in relation to political donations. On one view, an imputation of a legal wrong will increase the damage to reputation and go beyond the accepted boundaries of political debate. In Cruddas v Adams, Eady J. stated that people should be permitted to freely express opinions about the system of political finance, but should not "accuse any individual of committing criminal offences" without supporting evidence. ${ }^{98}$ However, the logic of transparency suggests that the more serious the allegation, then the stronger the case for public discussion. When discussing the public interest defence in Flood v Times, Lord Dyson stated that the public interest will weigh more heavily in favour of publication where there is an allegation of "crime or professional misconduct by a person in his performance of a public function". 99 The statements reveal an underlying tension between a desire to shield people from the harsh consequence of trial by public opinion, while empowering the public opinion to assess political conduct.

The boundaries of the law have not been fully tested in political speech cases. However, it appears that the courts impose some limits on the defences and are not willing to simply leave politicians to fend for themselves before the public. The courts recognise that the person behind the political reputation is entitled to some protection, which in some cases is required under Article 8 of the European Convention. ${ }^{100}$ Furthermore, the courts realise that in practice the liberalisation of libel can empower large media institutions, and are unwilling to give a blank cheque to the media. The question is whether the boundary post-libel reform is sufficient to allow public monitoring to function properly.

\section{The role of the court}

Another tension between defamation law and the transparency regime lies in the role of the court in settling the dispute. By invoking defamation law, the claimant asks the court to provide an authoritative resolution to the differing interpretations of events being advanced and of the terms of the allegations being made. ${ }^{101}$ To offer such a resolution, the court has to decide the meaning of the statement and, when the defence of truth is pleaded, whether the defamatory statement is correct. With publications alleging corruption, the court will have to decide the meaning of corruption and whether it has arisen on the facts. The complexities in addressing such questions were illustrated in the decision in Cruddas $v$ Calvert, in which the claimant was a former Treasurer of the Conservative Party who was the subject of a sting operation by The Sunday Times' Insight team of investigative reporters. The journalists posed as representatives of an international financial company looking to make investments in the UK and seeking to make contact with high-level members of the government. In a meeting, Cruddas told the journalists that donations could not buy access or influence. However, he also discussed the benefits of making a large donation, which included meeting senior politicians at social events, being listened to, and picking up

\footnotetext{
${ }^{98}$ Cruddas v Adams [2013] EWHC 145 at [9]. The case arose from a blogger's statements about Cruddas following a newspaper sting operation, which itself was the subject of a separate defamation in Cruddas v Calvert [2015] EWCA Civ 171; [2015] E.M.L.R. 16.

${ }^{99}$ Flood v Times Newspapers [2012] UKSC 11; [2012] 2 A.C. 273, at [195]

${ }^{100}$ See Pfeifer v Austria (2009) 48 E.H.R.R. 8; 24 B.H.R.C. 167 at [35]. Lindon v France (2008) 46 E.H.R.R. 35 at [57].

${ }^{101}$ R. Post, “Social Foundations of Defamation Law” (1986) 74 California Law Review 691, 712
} 
information. The Sunday Times published several articles and an editorial based on the sting, including a front-page headline "Tory Treasurer charges $£ 250,000$ to meet PM”. In the subsequent defamation litigation, the court found the article to be making an allegation of corruption, and the Court of Appeal found this to mean corruption in the broader ethical sense, as opposed to being limited to an allegation of illegal conduct. ${ }^{102}$

As the journalists relied on the defence of justification, they had to prove that Cruddas had breached the ethical standards as a matter of fact. The court had to decide what those ethical standards are, in order to assess whether the evidence supported the allegation. The judges therefore had to determine the very ethical questions that, the earlier discussion showed, provoke disagreement, rest on a view about the ideal workings of the political system, and which the public have a role in resolving. In Cruddas, the judges themselves disagreed on the ethical questions. At first instance, Tugendhat J. found that politicians were expected as a matter of ethics to comply with the legal rules and any additional standards the political actor had publicly adopted. ${ }^{103}$ In the Court of Appeal, Jackson L.J. thought the ethical requirements went beyond acting consistently with public statements. Jackson L.J. stated that access at social events is not unethical so long as no confidential information is disclosed, that the views of the donor are not given weight by virtue of giving money, and no commercial advantage is given to the donor. ${ }^{104}$ On this point, the Court of Appeal found that the journalists had established the truth of the allegations. ${ }^{105}$ The litigation in Cruddas demonstrates not only the complexity of defamation law, but also the complexity of the questions surrounding the ethics of political finance.

The discussion earlier showed that transparency gives the public the raw data to make their own assessments about the ethics of a donation. In defamation proceedings, the matter is taken out of the hands of the public and given to the court to define and resolve. Under earlier law, the public had some input into such decisions through the mechanism of jury trial in libel. However, the Defamation Act 2013 removes the assumption in favour of a jury in libel cases and the court has ruled that the discretion to order a jury trial should not be invoked simply as the claim touches on issues that are subject to political accountability. ${ }^{106}$ By taking the issue away from the public, politicians have a strong incentive to rely on non-political processes to restore reputation. In a background culture of cynicism, public opinion will often assume the guilt of the politician or the lobbyist, and once an allegation is made it will be difficult to shake off any lingering suspicion. By contrast, in libel the assumption is in favour of the accused and it is for the publisher to prove the truth of the allegation. The court then makes a formal ruling that brings some closure to the dispute. That, however, stands in contrast to the messy and inconclusive process of political debate that lies at the heart of the transparency rules. If the modern trend has been to "politicise" reputations by promoting free discussion, then reliance on libel can be seen as an attempt to "de-politicise" (or at least "re-privatise”) reputation by the

\footnotetext{
102 Cruddas v Calvert [2013] EWCA Civ 748; [2014] E.M.L.R. 5.

${ }^{103}$ Cruddas v Calvert [2013] EWHC 2298 at [83]: "The present system of party funding, whether desirable or not, is lawful and practical [...] This court cannot declare to be corrupt, as a matter of fact, the system of party funding authorised by Parliament and adopted by the Conservative and other parties”.

${ }^{104}$ Cruddas v Calvert [2015] EWCA Civ 171; [2015] E.M.L.R. 16 at [28].

105 Though Cruddas won in respect of allegations relating to the breach or evasion of the ban on foreign donations.

${ }^{106}$ Yeo v Times Newspapers [2014] EWHC 2853 (QB); [2015] 1 W.L.R. 971.
} 
taking the issue away from the cut and thrust of political debate and treating it as a matter of private rights to be settled by the courts. ${ }^{107}$

\section{CONCLUSION}

A change in political culture has featured throughout this article. Trust in politicians as a class is low and politicians cannot take their authority for granted. That culture has seen increasing levels of concern about the way political parties are financed. The concerns voiced in public debate often centre on allegations of corruption and undue influence. Whether a particular donation is corrupt is not settled and will depend on what we expect from the political system and individual politicians. It was in relation to this issue that the first role for public opinion was identified. The ethical standards expected of the politician and the types of external influence that are legitimate in a democracy are determined through a process of public debate. This process often occurs when members of the public discuss the latest party funding "scandals". The standards develop as the public becomes aware of fundraising practices and the conduct of politicians. The scrutiny of political conduct is central in deciding the meaning of corruption in any system.

The culture of mistrust means that the public is no longer happy to leave the monitoring and enforcement of ethical standards to the relevant authorities. Instead the public demands to see the evidence to decide for themselves whether any particular practice fulfils the ethical standards. This provides a rationale for the transparency regime in which donations are publicly disclosed. The idea is that the public, armed with information, will be able to decide whether a donation looks suspicious and impose a political sanction accordingly, which provides a second role for public opinion. The discussion has shown the limits of this approach. The data provided is limited, and needs to be supplemented with further contextual information. The system encourages constant monitoring of politicians and speculation about motives. In some cases the suspicion will be unwarranted, while in others genuinely unethical conduct will go undetected. The proliferation of rules also increases the number scandals in relation to issues of compliance. Far from deflating suspicions of the political class, the transparency regime has institutionalised the culture of mistrust. Nonetheless, further transparency is often advanced as the antidote to mistrust in other areas, such as lobbying. The discussion here has shown why such high hopes are unlikely to be met and that the shortcomings of transparency as a technique of regulation need to be recognised.

Opinions differ as to whether the cultural shift combing openness and mistrust is to be celebrated, or whether it damages the fabric of democracy. While the cultural change has been taking place over a number of decades, it has accelerated in the current media environment. John Keane observes how the culture of media abundance in the digital era has seen the rise of the "new muckrakers" characterised by "highintensity efforts by citizens, journalists and monitory institutions to bombard power holders with 'publicity' and 'public exposure"'. ${ }^{108}$ Under this view, the new media environment has "brawling, rowdy, rough-and-tumble qualities". ${ }^{109}$ While this can damage political reputations, Keane notes that it has "positive consequences"

\footnotetext{
${ }^{107}$ For discussion of “de-politicisation” more generally, see C. Hay, Why We Hate Politics (Cambridge 2007), pp.78-87.

108 J. Keane, Democracy and Media Decadence (Cambridge 2013), 40.

${ }^{109}$ Ibid., p.45.
} 
overall. ${ }^{110}$ The orientation towards scandals in political finance can be seen as one feature of this new culture. On this view, the constant monitoring, questioning and bruising of political actors is a tool for controlling political elites and reflects the empowerment of the citizens.

Others are less convinced of these positive effects. Flinders argues that this shift takes a "negative view of politics" in which "politicians are not to be trusted". 111 The culture is "driven by aggression and rejoices in the taking of political scalps". ${ }^{112}$ Flinders writes that the trend has been driven by the news media and "can be as, if not more, destructive to democratic politics than the suppression of the media would be". ${ }^{113}$ Under this view, power has flowed away from politicians, but the media is misusing its liberties to promote an attitude of suspicion that devalues the work of politicians and disengages citizens. Flinders calls for a more mature assessment of politics that acknowledges the difficult tasks performed by those in office and that recognises good conduct. ${ }^{114}$

This article has used political finance as a case study to examine the relationship between corruption, transparency and reputation rights, and the role of public opinion. The areas of law are interconnected. Laws facilitating the monitoring role of the public can have implications for rights to reputation and privacy, and vice versa. The tensions between the various areas of law are related to the contrasting views of politics mentioned above. The logic of the transparency regime points towards the empowerment of citizens and the loss of political control over the flow of information. The full implications of this change were not foreseen at the time the transparency regime was enacted. The recent liberalisation of libel law facilitates the monitoring of politicians and allows for inaccurate allegations to be made when the conditions of the public interest defence are fulfilled. In so far as it opens up the path for more robust criticisms, the law caters to the new political culture. However, the logic of defamation law and privacy is to view such freedom as a concession, rather than a goal to be pursued.

The liberalisation only goes so far and defamation law places limits on the "muckraking" and to some degree restores power to the holder of the reputation. The latter role can be in tension with the workings of the transparency regime by potentially curbing open debate on political ethics and removing public opinion as the main arbiter of those issues. The tension cannot be wished away by hoping that transparency can become a more precise mechanism. The solution may therefore lie in looking at alternative regulations, such as a cap on political donations. Such a measure may generate controversy and will not cover every situation where money is seen to secure political benefits. Transparency will remain as a strategy to combat corruption, albeit one that is often messy and inconclusive. Whether the costs are worth accepting depends on one's view about the types of monitoring power to be vested in public opinion in a representative democracy. The defamation cases that test these boundaries tend to arise out of political struggles to control the interpretation of events following a scandal. The outcomes of these struggles, however, have longerterm implications that reflect and help to shape the political culture.

\footnotetext{
110 Ibid., p.106.

${ }^{111}$ M. Flinders, Defending Politics (Oxford 2012), 44-45.

112 Ibid., p.44-45.

113 Ibid., p.144.

114 Ibid., p.46.
} 